\title{
Author Correction: Mortality outcomes with hydroxychloroquine and chloroquine in COVID-19 from an international collaborative meta-analysis of randomized trials
}

Cathrine Axfors, Andreas M. Schmitt (1), Perrine Janiaud, Janneke van't Hooft (1), Sherief Abd-Elsalam (D), Ehab F. Abdo (1D, Benjamin S. Abella (1), Javed Akram, Ravi K. Amaravadi, Derek C. Angus, Yaseen M. Arabi, Shehnoor Azhar, Lindsey R. Baden, Arthur W. Baker (D), Leila Belkhir, Thomas Benfield (D, Marvin A. H. Berrevoets, Cheng-Pin Chen (D), Tsung-Chia Chen (D), Shu-Hsing Cheng (D), Chien-Yu Cheng, WeiSheng Chung (D), Yehuda Z. Cohen (D), Lisa N. Cowan, Olav Dalgard, Fernando F. de Almeida e Val, Marcus V. G. de Lacerda (D, Gisely C. de Melo, Lennie Derde (1), Vincent Dubee (D), Anissa Elfakir, Anthony C. Gordon (1), Carmen M. Hernandez-Cardenas (1), Thomas Hills (D, Andy I. M. Hoepelman, YiWen Huang, Bruno Igau, Ronghua Jin, Felipe Jurado-Camacho, Khalid S. Khan, Peter G. Kremsner, Benno Kreuels (1), Cheng-Yu Kuo, Thuy Le (D), Yi-Chun Lin, Wu-Pu Lin (1), Tse-Hung Lin, Magnus Nakrem Lyngbakken (1), Colin McArthur, Bryan J. McVerry (D), Patricia Meza-Meneses (D), Wuelton M. Monteiro, Susan C. Morpeth, Ahmad Mourad (1), Mark J. Mulligan, Srinivas Murthy, Susanna Naggie, Shanti Narayanasamy (1), Alistair Nichol, Lewis A. Novack, Sean M. O'Brien, Nwora Lance Okeke, Léna Perez, Rogelio Perez-Padilla, Laurent Perrin (1), Arantxa Remigio-Luna, Norma E. Rivera-Martinez (1D, Frank W. Rockhold (D), Sebastian Rodriguez-Llamazares (D), Robert Rolfe, Rossana Rosa, Helge Røsjø, Vanderson S. Sampaio (1), Todd B. Seto, Muhammad Shahzad, Shaimaa Soliman, Jason E. Stout (1), Ireri Thirion-Romero, Andrea B. Troxel, Ting-Yu Tseng, Nicholas A. Turner (D), Robert J. Ulrich (1), Stephen R. Walsh (1), Steve A. Webb, Jesper M. Weehuizen, Maria Velinova, Hon-Lai Wong, Rebekah Wrenn, Fernando G. Zampieri (D), Wu Zhong (1), David Moher (D, Steven N. Goodman, John P. A. Ioannidis (1) \& Lars G. Hemkens (1)

Correction to: Nature Communications https://doi.org/10.1038/s41467-021-22446-z, published online 15 April 2021.

The original version of this Article contained an error in the spelling of the author Muhammad Shahzad, which was incorrectly given as Muhammad Shehzad. This has now been corrected in both the PDF and HTML versions of the Article. 
(c) Open Access This article is licensed under a Creative Commons Attribution 4.0 International License, which permits use, sharing, adaptation, distribution and reproduction in any medium or format, as long as you give appropriate credit to the original author(s) and the source, provide a link to the Creative Commons license, and indicate if changes were made. The images or other third party material in this article are included in the article's Creative Commons license, unless indicated otherwise in a credit line to the material. If material is not included in the article's Creative Commons license and your intended use is not permitted by statutory regulation or exceeds the permitted use, you will need to obtain permission directly from the copyright holder. To view a copy of this license, visit http://creativecommons.org/licenses/by/4.0/.

(C) The Author(s) 2021 